
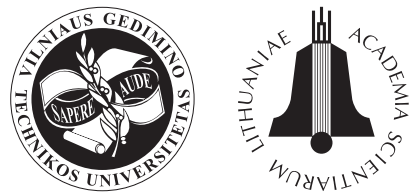

TRANSPORT

2010

25(2): $171-177$

\title{
ROUTE PLANNING METHODOLOGY OF AN ADVANCED TRAVELLER INFORMATION SYSTEM IN VILNIUS CITY
}

\author{
Marius Jakimavičius ${ }^{1}$, Marija Burinskienè ${ }^{2}$ \\ Dept of Urban Engineering, Vilnius Gediminas Technical University, \\ Sauletekio al. 11, LT-10223 Vilnius, Lithuania \\ E-mails: ${ }^{1}$ mjakimavicius@hnit-baltic.lt; ${ }^{2}$ marija.burinskiene@vgtu.lt
}

Received 20 December 2009; accepted 20 May 2010

\begin{abstract}
As a subsystem of an Intelligent Transportation System (ITS), an Advanced Traveller Information System (ATIS) disseminates real-time traffic information to travellers. To help them with making better decisions on choosing their routes, a strong need to predict traffic congestion and to disseminate the predicted congestion information relating to travellers can be seen. This paper describes a methodology used by drivers for calculating an optimal driven route in Vilnius. The paper discusses how ATIS systems will likely evolve the experience of Information Service Providers (ISP) and optimal route planning calculations. A few methods of route planning have been taken into account. The paper presents the following types of route calculation: 1) the shortest route; 2) the quickest route; 3 ) the quickest forecasted route according to historical traffic information. Also, the paper deals with the architecture of the WEB based information system for drivers in Vilnius and analyzes data on traffic workflow. Furthermore, a comprehensive route planning procedure that forecasts data on driving time considering historical traffic is followed.
\end{abstract}

Keywords: advanced traveller information system, route planning, real-time traffic data, travel time.

\section{Introduction}

The deployment and operational efficiency of Advanced Traveller Information Systems (ATIS) entail the accurate modelling of driver route choice behaviour under real-time traffic information and the calibration of the associated model parameters (Ran 2000). Driver enroute routing decisions are influenced by personal attributes, response attitude to the supplied information and situational factors such as time-of-day, weather conditions, trip purpose and ambient traffic conditions (Jarašūnienè 2007; Jarašūnienè and Jakubauskas 2007). The latent preferences of drivers towards possible routes are typically difficult to capture accurately because they are significantly affected by past experience, a subjective interpretation of traffic information provided and personal attitudes dynamically changing traffic conditions. The most existing models are limited in their ability to capture the interacting effects of various situational factors and typically cannot adjust model parameters in a within-day context (Ruiz et al. 2004; Daunoras et al. 2008; Akgüngör 2008a, 2008b; Matis 2008, 2010; Kinderytė-Poškienè and Sokolovskij 2008; Gowri and Sivanandan 2008; Niewczas et al. 2008; Mesarec and Lep 2009; Çalıșkanelli et al. 2009; Junevičius and Bogdevičius 2009). The latter capability is critical for consistency-checking procedures for the real-time operational deployment of advanced information systems. Driver route choice models under information provision have traditionally adopted the econometric theory of random utility maximization (Ben-Akiva and Lerman 1985).

Mahmassani and Liu (1999) used a multinomial framework to model and calibrate commuter joint pre trip departure time and route-switching behaviour in response to ATIS based on data obtained from a laboratory interactive dynamic simulator. The study suggests that commuters switch routes if the expected travel time savings exceed indifference band varying with remaining trip time to destination. Abdel-Aty et al. (1997) developed logic models to capture the effect of traffic information on commuter route choice using stated preference data. They analyzed the influence of travel time variability and the effect of information on it. The choice between a longer route with reliable travel time and a shorter route with uncertain travel time is investigated 
based on the notions of risk aversion and risk-taking in route choice. Peeta and Gedela (2001) produced logic models to predict drivers' decisions on route diversion under traffic information provided via variable message signs. They showed that a strong correlation existed between message content and driver route diversion decisions which could be a control variable in operational strategies to enhance network performance. Khattak and De Palma (1997) use the ordered probity models to investigate the effect of the weather on traveller behaviour and suggest that commuters change their travel patterns systematically under adverse weather.

In the context of route driver behaviour under information provision, qualitative phenomena such as inertia, compliance, delusion, freezing and perception of traffic information have been recently identified. Srinivasan and Mahmassani (2000) made a multinomial model with a nested choice structure to examine inertia and compliance. Inertia represents propensity to remain on the current path while compliance represents the tendency to choose the path recommended by the traffic information system.

GIS could be also applied searching for rational car routes in case it is necessary to be at a specific spot of the network at specific time. The system offers a rational route, departure time and calculated expenses depending on the set parameters and real-time traffic data to the user. In other papers analyzing the application of GIS technologies for sustainable transportation, an application of multi-modal networks could be spotted. They are applied when solving tasks for choosing routes within the overall urban transport system and include cars, public transport, railway transport and even pedestrians (Abdelghany et al. 2001; Geertman and Van Eck 1995). An assessment of transport jams on the street network is necessary when solving the task of choosing the fastest route. A search algorithm the results of which depend on the time set by a system user has been programmed as street capacity is different depending on the time of the day (Peeta and Yu 2005; Jakimavičius and Mačerinskienè 2006; Jakimavičius and Burinskienè 2009). General public might be the user of IS which helps with choosing a rational driving route. When applying ESRI technologies, a system user is given WEB based GIS application the functioning of which allows setting the start and end of the trip and interim stopping places (if necessary). The IS user is given a map with a marked rational driving route according to real-time traffic data. The system also could forecast a rational driving route taking into consideration historical traffic data.

\section{Transport System Indicators in Vilnius City and a Description of an Information System for Drivers}

Growing Lithuanian economy and the increasing quality of living conditions prompt population mobility, motorization level and increasingly high transport flow on streets and roads across the country (Jakimavičius and Burinskienè 2007; Jakimavičius and Burinskiené 2009; Burinskienè and Paliulis 2003).
The average percentage number of automobiles in Vilnius city grows about $3 \%$ per year. The number of individual cars in Vilnius rose from 265 automobiles for 1000 inhabitants in 1999 up to 550 in 2008. A sharp bounce of motorization level invokes a lot of transportation problems. The main transport system indicators for Vilnius city are presented in Table 1.

Table 1. Transport system indicators for Vilnius city in 1999, 2005 and 2008

\begin{tabular}{llll}
\hline \multicolumn{1}{c}{ Indicator } & 1999 & \multicolumn{1}{c}{2005} & \multicolumn{1}{c}{2008} \\
\hline Street network density $\left(\mathrm{km} / \mathrm{km}^{2}\right)$ & 1.9 & 2.4 & 3.1 \\
\hline $\begin{array}{l}\text { Public transport network density } \\
\left(\mathrm{km} / \mathrm{km}^{2}\right)\end{array}$ & 0.55 & 0.62 & 0.74 \\
\hline $\begin{array}{l}\text { Average traffic flow in peak hours } \\
\text { (aut./h) }\end{array}$ & 1275 & 1521 & 1550 \\
\hline $\begin{array}{l}\text { Percentage number of trucks in } \\
\text { average flow }\end{array}$ & 3.4 & 2.4 & 2.1 \\
\hline $\begin{array}{l}\text { Average speed in peak traffic flow } \\
(\mathrm{km} / \mathrm{h})\end{array}$ & 37.5 & 29.3 & 31 \\
\hline Modal split & 31.3 & 34.8 & 33.1 \\
\hline - pedestrian trips in \% & 0.3 & 0.3 & 0.3 \\
\hline - trips by bicycles in \% & 45.4 & 34.2 & 40.9 \\
\hline - trip by public transport in \% & 23.0 & 30.7 & 25.7 \\
\hline - trips by car in \% & 21.3 & 13.2 & 10.1 \\
\hline Transit of trucks in peak hours in \%
\end{tabular}

Many scientific researches analyze a transport information system from the point of intelligent transportation according route planning functionality (Szücs 2009).

Vilnius information system developed for drivers has route planning functionality. A system user can perform the shortest, the quickest based on real-time traffic information and the quickest forecasted route in accordance with historical traffic information data. The interface of Vilnius information system for drivers is presented in Fig. 1.

\section{Rational Route Planning Algorithms}

The road network (as a part of infrastructure) can be represented as a graph. There are some shortest path algorithms that allow fast point-to-point queries in graphs using pre-processed data. A standard algorithm for this problem is the one developed by Dijkstra algorithm (Dijkstra 1959).

Other scientists adapted Dijkstra's shortest path algorithm to decrease the size of search space (Cherkassy et al. 1996). The algorithm was the first to use a bi directional search method. This algorithm consists of a forward search from an origin node to the destination node and a reverse search from the destination to origin node.

The best first search has been a framework for heuristics which speeds up algorithms using semantic information about a domain. It has been explored in database 


\section{Vilniaus miesto vairuotojų informacinè sistema}

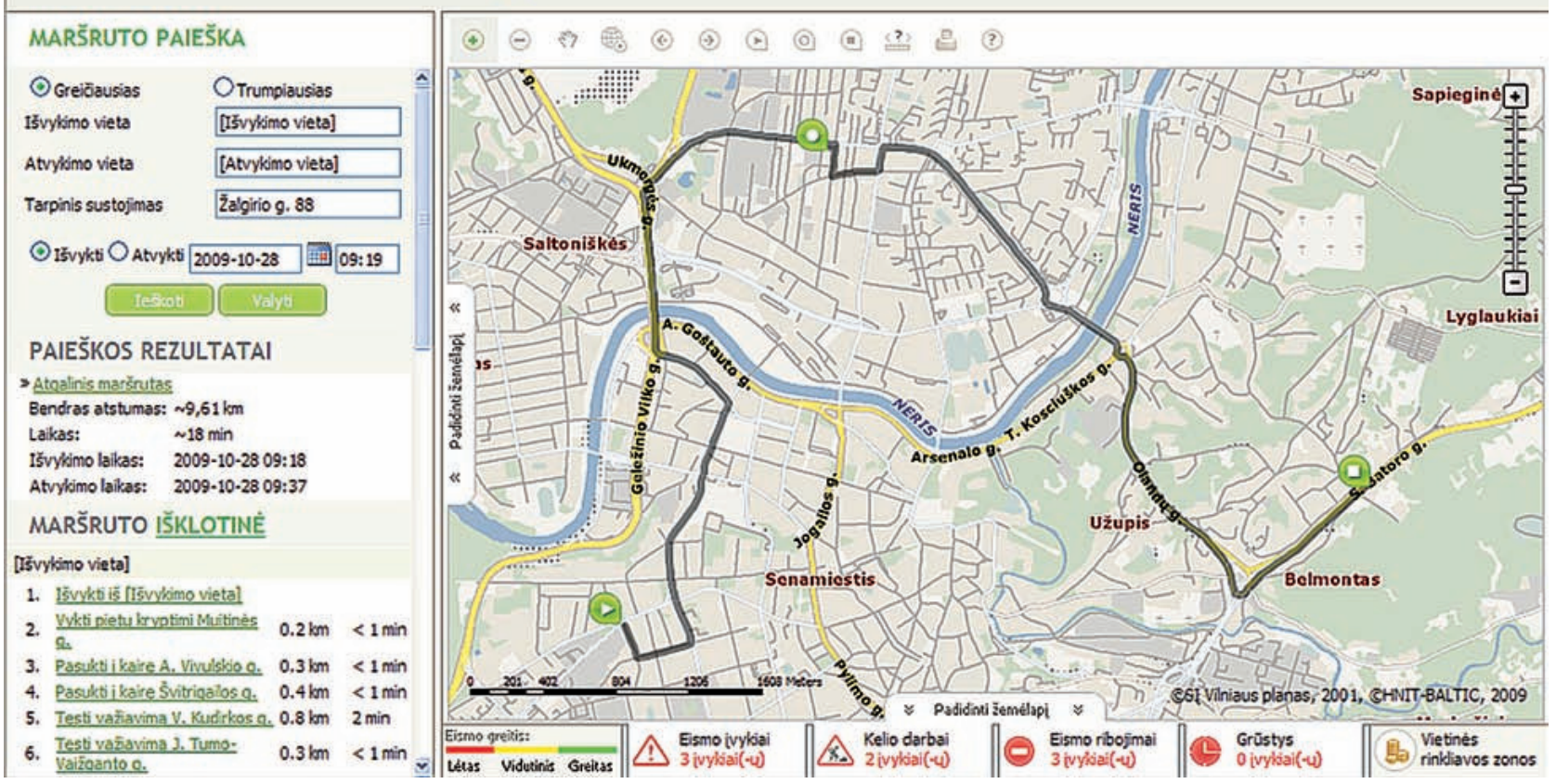

Fig. 1. An example of the Internet information system for drivers (in Lithuanian)

context for single pair path computation. $\mathrm{A}^{*}$ is a special case of the best first search algorithm. It uses an estimator function $f(u, d)$ to estimate the cost of the shortest path between nodes $u$ and $d$. $\mathrm{A}^{\star}$ has been quite influential due to its optimality properties (Goldberg and Harrelson 2005).

The Arc-Flags (Möhring et al. 2005; Köhler et al. 2006) method is a modified Dijkstra algorithm in order to avoid exploring unnecessary paths. This means the procedure checks the flag entry of the corresponding target region (the region where the target node $t$ belongs to) every time before Dijkstra algorithm wants to traverse an arc which is the only modification to the standard Dijsktra algorithm.

Highway Hierarchies (Sanders and Schultes 2006) uses the concept of local search. This approach is a purely hierarchical method, i. e. an approach trying to exploit the hierarchy of a graph. The contraction phase builds the core of a level and adds shortcuts to the graph. The identification of highway edges is done by local Dijkstra executions.

In order to perform rational route search in Vilnius information system for drivers, the weighted Dijkstra method have been employed. This method corresponds to further biasing forward search towards the destination. Road network edges have assigned the weighted network attribute parameter (time or length). A route calculation mechanism tries to minimize the total sum of weight associated with a specific road network edge.

\section{The Methodology Used for Making Route Planning Functional in Vilnius ATIS}

Standard ESRI ArcGIS Server Network extension enables to perform optimal route calculation tasks. It is possible to make the quickest route calculations because attribute data on road and street segments are periodically updated by driving time information from the equipped sensors. Fig. 2 presents traffic flow data from traffic sensors equipped on a street to road network GIS data base.

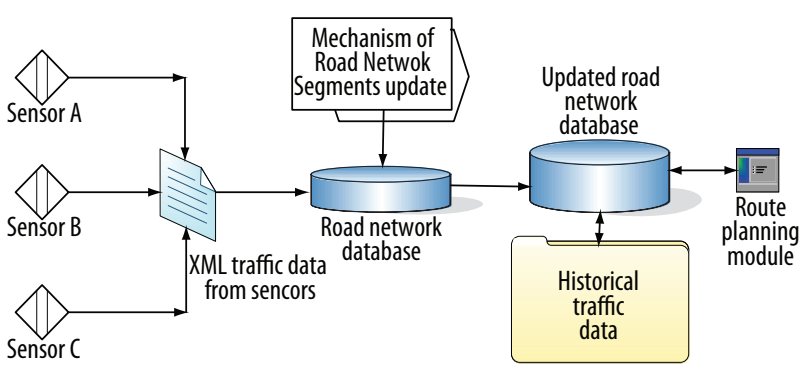

Fig. 2. Traffic data workflow

All data on driving time from traffic sensors is generated by one xml file. Each minute, a new xml file is generated. Accordingly, xml file road network database is updated periodically in 5 minutes. The updated road network database contains data on one week travel time in one hour intervals and there are two fields updated periodically in 5 minutes. Thus, these fields contain almost real-time traffic data. Historical travel time data, which is older than one week, is stored in a separate table. The system takes into account data on real time, driving time and historical driving time obtained in street segments according to the user entered optimal route query parameters. Also, the system allows combining the planned route with an alternative for public transport. WEB application in a new window shows the 
optimal route to public transport in a digital map. The types of public transport vehicles and time table schedulers are also presented. Fig. 3 discloses a route planning activity diagram of an advanced traveller information system in Vilnius city.

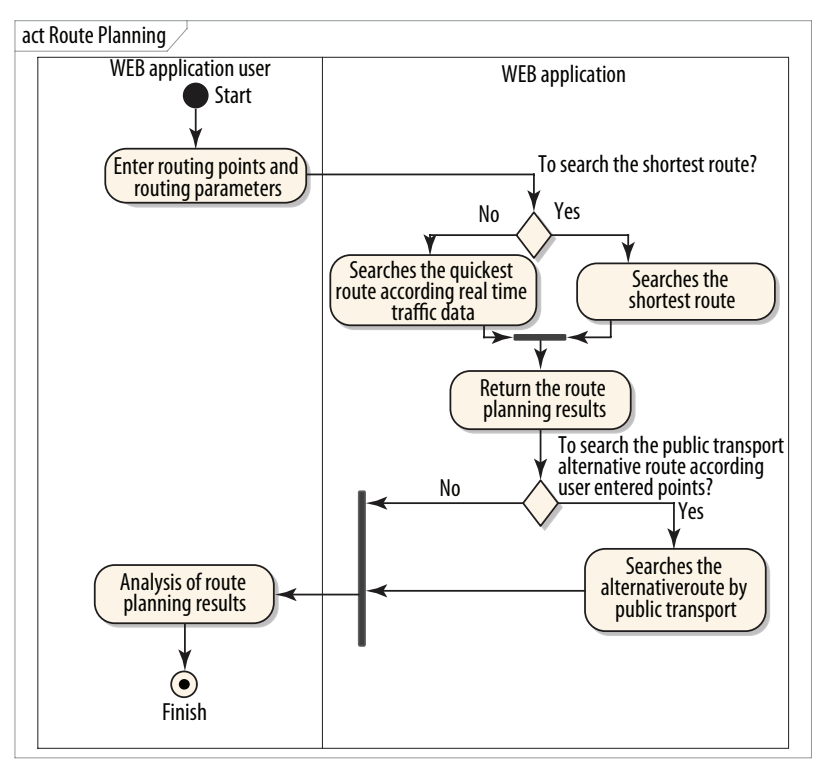

Fig. 3. Route planning activity diagram

\section{Mathematical Model for Optimal Route Calculation Tasks}

The created GIS transportation data model and developed WEB mapping application allow for public users making the following combinations of optimal driving route calculation:

- the shortest optimal route;

- the fastest optimal route according to almost real-time driving time data;

- optimal driving route according to prognosis alternatives using historical driving time data.

The above mentioned optimal route calculation tasks belong to the branch of linear network optimization. The main principal of the shortest and quickest optimal route calculation procedure is that software tries to find the route from the start to the end point by minimizing the weights of road or street network segments. All those weights are stored in the attribute table of GIS road and street network database.

Optimal route modelling tasks have the following features (Kalanta 2003):

- a junction with road and street network matches to the peak of the graph and a section of the street segment matches to the edge of the graph;

- road network and street database have $m$ peaks (junctions) on Fig. 4 and evaluated weights between network peaks $w_{i j}$. According to weight information, we can find optimal routes between start peak $i=1$ and the end peak of route $i=m$;

- weight $w_{i j}$ could be applied considering differ- ent values of parameters such as the distance from peak $i$ to peak $j$, time attribute necessary to make a trip from peak $i$ to peak $j$. Also, traffic volume from peak $i$ to peak $j$ as well as other interesting traffic conditions could be evaluated;

- variables $x_{i j}$ only may have 0 or 1 values. If the shortest, quickest or the route that has the least traffic volume passes peaks $i$ and $j$, then, $x_{i j}=1$ if the route does not go through peaks $i$ and $j$, then $x_{i j}=0$;

$-N_{i}^{-}$is the collection $\mathrm{j}$ of streets going from peak $i ; N_{i}^{+}$is the collection $\mathrm{j}$ of streets going to peak $i$ :

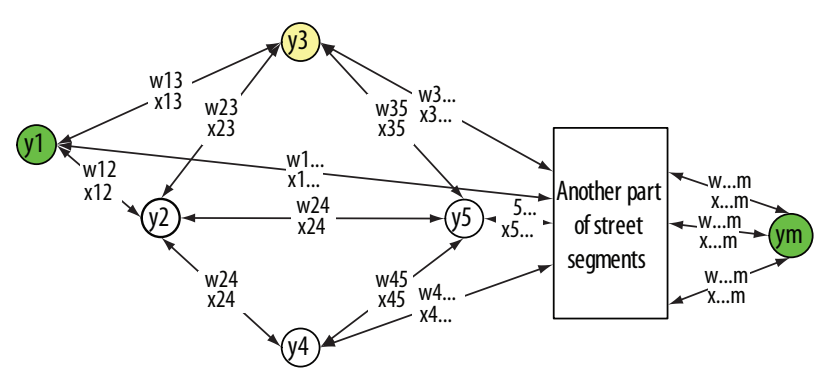

Fig. 4. The street network scheme with weights attributed to sections

When the user of WEB application performs the shortest, the quickest or the optimal route according to historical traffic data, the system computes the optimal route following the below mathematical model:

$$
\min f(x)=\sum_{i=1}^{m-1} \sum_{j \in N_{i}} w_{i j} x_{i j}-\text { objective function, }
$$

when:

$$
\begin{aligned}
& \sum_{k \in N_{1}^{-}} x_{1 j}=1, i=1 \\
& \sum_{k \in N_{i}^{-}} x_{i j}-\sum_{k \in N_{i}^{+}} x_{i j}=0, x_{i j}=0 \\
& x_{i j} \geq 0 ; i=1,2,3, \ldots, m ; j=2,3, \ldots, m .
\end{aligned}
$$

The objective function minimizes the route depending on the values of parameter $w_{i j}$. Weight is a number value containing such values as the length of the street segment, driving time necessary to go through a particular line segment, the historical driving time of a specific road or street segment. WEB application computes the shortest driving distance route when weight $w_{i j}$ is filled with street network segment length values. When $w_{i j}$ is filled with road and street network driving time values, WEB application computes the quickest driving route.

Restrictions (1) are used to keep the equation in equilibrium. It describes a condition that only one direction should be used from the first peak in the optimal route calculation procedure. Equation (2) means that if a certain road and street junction is taken to come to a certain peak, another junction is taken to leave a certain graph peak. 


\section{Application and Results of the Method Performing the Quickest Driving Route Calculation}

In order to find the optimal driving route in the road and street network between the start and end points (the shortest and the quickest according to the almost realtime data and the quickest future prognosis according to historical driving time data), it is necessary to evaluate the weights $w_{i j}$ of the network segments. The number values (segment length, driving time) should be attributed to the street sections.

The calculation method of the quickest driving route is shown in the below figure. Let's presume that we have the street network fragment shown in Fig. 5.

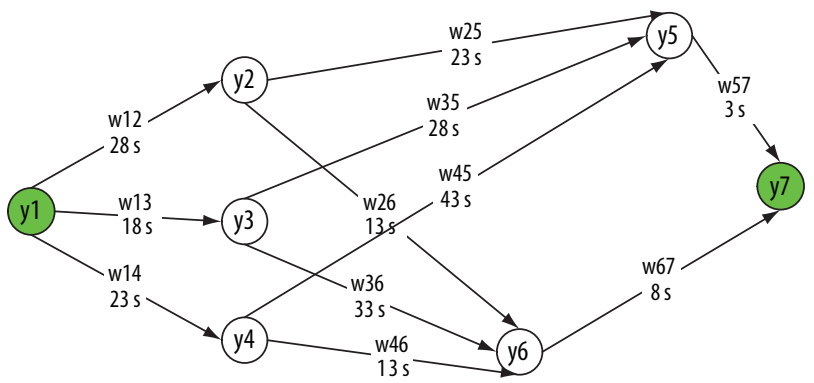

Fig. 5. Street network fragment with section weights

The optimal driving route could be estimated when driving time value for each network segment is known. Besides, it is necessary to know traffic restrictions including one way directions, restricted turns and two level crossings.

A mathematical model for performing the calculation of the quickest driving route is as follows:

$$
\begin{aligned}
& f(x) \min =w_{12} \cdot x_{12}+w_{13} \cdot x_{13}+w_{14} \cdot x_{14}+w_{25} \cdot x_{25}+w_{35} \cdot x_{35}+ \\
& w_{45} \cdot x_{45}+w_{26} \cdot x_{26}+w_{36} \cdot x_{36}+w_{46} \cdot x_{46}+w_{57} \cdot x_{57}+w_{67} \cdot x_{67},
\end{aligned}
$$

where: $w_{i j}$ - driving time in road and street network segments; $x_{i j}$ - route parameter, assumed values (0 or 1$)$.

The limitation of conditions:

$$
\begin{aligned}
& x_{12}+x_{13}+x_{14}=1 ; \\
& -x_{12}+x_{25}+x_{26}=0 ; \\
& -x_{13}+x_{35}+x_{36}=0 ; \\
& -x_{14}+x_{45}+x_{46}=0 ; \\
& -x_{25}-x_{35}-x_{46}+x_{57}=0 \\
& -x_{26}-x_{36}-x_{46}+x_{67}=0 \\
& x_{\mathrm{ij}} \geq 0
\end{aligned}
$$

The 7 th node does not need any restrictions, as in this case, the equation would have linear dependence.

\begin{tabular}{|c|c|}
\hline 1st iteration & $y_{1}=0$ \\
\hline \multirow[t]{3}{*}{ 2nd iteration } & $y_{2}=w_{12}=28 \mathrm{sec}$ \\
\hline & $y_{3}=w_{13}=18 \mathrm{sec}$ \\
\hline & $y_{4}=w_{14}=23$ sec.. \\
\hline \multirow[t]{2}{*}{ 3rd iteration } & $\begin{array}{l}y_{5}=\min \left(y_{2}+w_{25}, y_{3}+w_{35}, y_{4}+w_{45}\right)= \\
\min (28+23, \underline{18+28}, 23+43)=46 \text { sec.; }\end{array}$ \\
\hline & $\begin{array}{l}y_{6}=\min \left(y_{2}+w_{26}, y_{3}+w_{36}, y_{4}+w_{46}\right)= \\
\min (28+13,18+33, \underline{23+13})=36 \text { sec. }\end{array}$ \\
\hline 4th iteration & $\begin{array}{l}y_{7}=\min \left(y_{5}+w_{57}, y_{6}+w_{67}\right)= \\
\min (46+3, \underline{36+8})=44 \text { sec. }\end{array}$ \\
\hline
\end{tabular}
The calculation of the optimal quickest driving route was performed using Dejkstra algorithm (Table 2).

The quickest route from peak 1 to peak 7 passes through graph peaks (junctions) 1, 4, 6, 7 and travel time is $44 \mathrm{~s}$. The graphical representation of the calculation results is presented in Fig. 6.
Table 2. Calculation of the optimal (the quickest) driving route

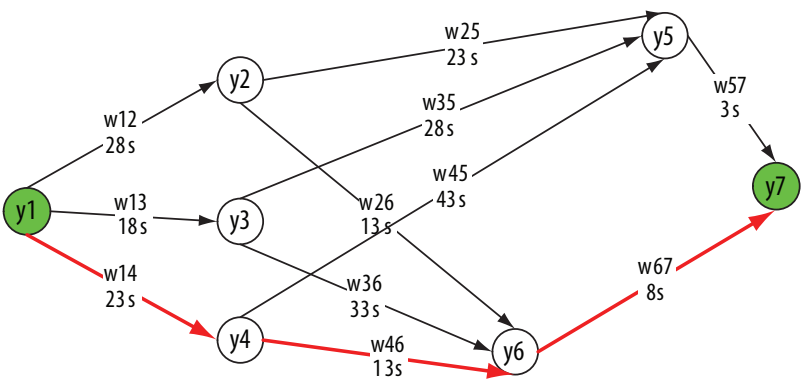

Fig. 6. Calculation results of the quickest route

\section{Conclusions}

1. The created WEB application for optimal driving route calculation can help the WEB user to find and choose the optimal route depending on optimality criteria chosen by the user: the shortest route, the quickest route according to the present traffic situation and the quickest route that has minimal driven time in agreement with historical traffic data.

2. Dijkstra algorithm has been applied to make calculations finding the optimal driving route. Street sections have been given weights in the database: street segment length, driving time necessary to pass street edge and historical driving time needed to go through the street segment when performing a route calculation task for the nearest future.

3. The method of driving time estimation is developed calculating the optimal driving route under conditions when the street segment has different traffic restrictions such as one-way traffic, restricted turns, prohibited traffic in a particular section.

4. The development of an automatic traffic management system in Vilnius city allowed increasing the average speed of traffic during peak traffic flow by $6 \%$. The considerable growth in traffic speed is registered in the street sections of Vilnius city traffic corridors where traffic speed increased more than $6 \%$, whereas in the street sections crossing traffic corridors, traffic speed decreased about 3\%. An automatic traffic light management system arranged in the corridors and determined priority for traffic flow going through 
the corridors are the main reasons for the encountered situation.

5. The developed mechanism for a rational choice of the route and designed vector database are published on the general GIS for public use with the help of ESRI technologies. Also, GIS database and a mechanism of updating the road network traffic database could be successfully adapted in other Internet information systems.

\section{References}

Abdel-Aty, M. A.; Kitamura, R.; Jovanis, P. P. 1997. Using stated preference data for studying the effect of advanced traffic information on drivers' route choice, Transportation Research Part C: Emerging Technologies 5(1): 39-50. doi:10.1016/S0968-090X(96)00023-X

Abdelghany, A. F.; Mahmassani, H. S.; Chiu, Y.-C. 2001. Spatial micro-assignment of travel demand with activity/ trip chains, Transportation Research Record 1777: 36-46. doi:10.3141/1777-04

Akgüngör, A. P. 2008a. A new delay parameter dependent on variable analysis periods at signalized intersections. Part 1: Model development, Transport 23(1): 31-36. doi:10.3846/1648-4142.2008.23.31-36

Akgüngör, A. P. 2008b. A new delay parameter dependent on variable analysis periods at signalized intersections. Part 2: Validation and application, Transport 23(2): 91-94. doi:10.3846/1648-4142.2008.23.91-94

Ben-Akiva, M.; Lerman, S. R. 1985. Discrete Choice Analysis: Theory and Application to Travel Demand. 1st edition. The MIT Press. 384 p.

Burinskiene, M.; Paliulis, G. 2003. Consistents of car's parking in Lithuanian towns, Transport 18(4): 174-181.

Çalışkanelli, P.; Özuysal, M.; Tanyel, S.; Yayla, N. 2009. Comparison of different capacity models for traffic circles, Transport 24(4): 257-264. doi:10.3846/1648-4142.2009.24.257-264

Cherkassy, B. V.; Goldberg, A. V.; Radzik, T. 1996. Shortest paths algorithms: Theory and experimental evaluation, Mathematical Programming 73(2): 129-174. doi:10.1007/BF02592101

Daunoras, J.; Bagdonas, V.; Gargasas, V. 2008. City transport monitoring and routes optimal management system, Transport 23(2): 144-149. doi:10.3846/1648-4142.2008.23.144-149

Dijkstra, E. W. 1959. A note on two problems in connexion with graphs, Numerische Mathematik 1: 269-271. doi:10.1007/BF01386390

Goldberg, A. V.; Harrelson, C. 2005. Computing the shortest path: $\mathrm{A}^{*}$ meets graph theory, in 16th Annual ACM-SIAM Symposium on Discrete Algorithms (SODA'05), 156-165.

Gowri, A.; Sivanandan, R. 2008. Evaluation of left turn channelization at a signalized intersection under heterogeneous traffic conditions, Transport 23(3): 221-229. doi:10.3846/1648-4142.2008.23.221-229

Geertman, S. C. M.; Van Eck, J. R. R. 1995. GIS and models of accessibility potential: an application in planning, International Journal of Geographical Information Systems 9(1): 67-80. doi:10.1080/02693799508902025

Jakimavičius, M.; Burinskiene,, M. 2009. A GIS and multi-criteria-based analysis and ranking of transportation zones of Vilnius city, Technological and Economic Development of Economy 15(1): 39-48. doi:10.3846/1392-8619.2009.15.39-48

Jakimavičius, M.; Burinskiené, M. 2007. Automobile transport system analysis and ranking in Lithuanian administrative regions, Transport 22(3): 214-220.
Jakimavičius, M.; Mačerinskienè, A. 2006. A GIS-based modelling of vehicles rational routes, Journal of Civil Engineering and Management 12(4): 303-309.

Jarašūnienè, A. 2007. Research into intelligent transport systems (ITS) technologies and efficiency, Transport 22(2): 61-67.

Jarašūnienè, A.; Jakubauskas, G. 2007. Improvement of road safety using passive and active intelligent vehicle safety systems, Transport 22(4): 284-289.

Junevičius, R.; Bogdevičius, M. 2009. Mathematical modelling of network traffic flow, Transport 24(4): 333-338. doi:10.3846/1648-4142.2009.24.333-338

Kalanta, S. 2003. Taikomosios optimizacijos pagrindai. Tiesiniu uždaviniu formulavimas ir sprendimo metodai: vadovèlis [Basics of Consiliatory Optimization. Formulation of Linear Tasks and Solution Methods: Tutorial]. Vilnius: Technika. 336 p. (in Lithuanian).

Khattak, A. J.; De Palma, A. 1997. The impact of adverse weather conditions on the propensity to change travel decisions: A survey of Brussels commuters, Transportation Research Part A: Policy and Practice 31(3): 181-203. doi:10.1016/S0965-8564(96)00025-0

Kinderytė-Poškienè, J.; Sokolovskij, E. 2008. Traffic control elements influence on accidents, mobility and the environment, Transport 23(1): 55-58.

doi:10.3846/1648-4142.2008.23.55-58

Köhler, E.; Möhring, R. H.; Schilling, H. 2006. Fast point-to-point shortest path computation with arc-flags, in 9th DIMACS Challenge on Shortest Paths. 27 p. Available from Internet: $<$ www.dis.uniroma1.it/ challenge9/papers/kohler.pdf>.

Mahmassani, H. S.; Liu, Y.-H. 1999. Dynamics of commuting decision behavior under advanced traveller information systems, Transportation Research Part C: Emerging Technologies 7(2-3): 91-107. doi:10.1016/S0968-090X(99)00014-5

Matis, P. 2010. Finding a solution for a complex street routing problem using the mixed transportation mode, Transport 25(1): 29-35. doi:10.3846/transport.2010.05

Matis, P. 2008. Decision support system for solving the street routing problem, Transport 23(3): 230-235. doi:10.3846/1648-4142.2008.23.230-235

Mesarec, B.; Lep, M. 2009. Combining the grid-based spatial planning and network-based transport planning, Technological and Economic Development of Economy 15(1): 60-77. doi:10.3846/1392-8619.2009.15.60-77

Möhring, R. H.; Schilling, H.; Schütz, B.; Wagner, D.; Willhalm, T. 2005. Partitioning graphs to speed up Dijkstra's algorithm, Lecture Notes in Computer Science 3503: 189-202. doi:10.1007/b136461

Niewczas, A.; Koszalka, G.; Wrona, J.; Pieniak, D. 2008. Chosen aspects of municipal transport operation on the example of the city of Lublin, Transport 23(1): 88-90. doi:10.3846/1648-4142.2008.23.88-90

Peeta, S.; Gedela, S. 2001. Real-time variable message sign-based route guidance consistent with driver behavior, Transportation Research Record 1752: 117-125. doi:10.3141/1752-16

Peeta, S.; Yu, J. W. 2005. A hybrid model for driver route choice incorporating en-route attributes and real-time information effects, Networks and Spatial Economics 5(1): 21-40. doi:10.1007/s11067-005-6660-9

Ran, B. 2000. Using traffic prediction models for providing predictive traveller informatikon, International Journal of Technology Management 20(3-4): 326-339. doi:10.1504/IJTM.2000.002870 
Ruiz, R.; Maroto, C. ; Alcaraz, J. 2004. A decision support system for a real vehicle routing problem, European Journal of Operational Research 153(3): 593-606. doi:10.1016/S0377-2217(03)00265-0

Sanders, P.; Schultes, D. 2006. Engineering highway hierarchies, Lecture Notes in Computer Science 4168: 804-816. doi:10.1007/11841036_71

Srinivasan, K. K.; Mahmassani, H. S. 2000. Modeling inertia and compliance mechanisms in route choice behavior under real-time information, Transportation Research Record 1725: 45-53. doi:10.3141/1725-07

Szücs, G. 2009. Developing co-operative transport system and route planning, Transport 24(1): 21-25. doi:10.3846/1648-4142.2009.24.21-25 